\title{
Sponges from North Borneo and their bioactivity against human colorectal cancer cells
}

\author{
Yoong-Soon Yong1, Swee-Cheng Lim², Ping-Chin Lee ${ }^{3}$ and Yee-Soon Ling ${ }^{*}$ \\ ${ }^{1}$ Biotechnology Research Institute, Universiti Malaysia Sabah, Jalan UMS, 88400 Kota Kinabalu, Sabah, Malaysia. \\ ${ }^{2}$ Tropical Marine Science Institute, National University of Singapore, 18 Kent Ridge Road, S2S, Singapore 119227, \\ Singapore. \\ ${ }^{3}$ Faculty of Science and Natural Resources, Universiti Malaysia Sabah, Jalan UMS, 88400 Kota Kinabalu, Sabah, \\ Malaysia.
}

*Corresponding author: lingyeesoon@ums.edu.my

\begin{abstract}
Sponges are major source of numerous cytotoxic compounds that are used for defence as well as adaptation to the environment. Numerous studies have discovered compounds from sponge extracts that were effective against a wide range of cancer cells. In this study, a total of 23 sponges comprising of 19 species were collected from Northeast Borneo. Sponges were treated and extracted using modified Folch extraction method, followed by cytotoxicity assay to determine their effectiveness against different colorectal cancer cells. Our results demonstrate that Monanchora clathrata, Dysidea sp., and Jaspis sp. possess different degrees of cytotoxicity against a wide range of human colorectal cancer cells. Monanchora clathrata (KDT07), Dysidea sp. (KDT09), and Jaspis sp. (KDT18) are among the demosponges which possess significant cytotoxicity against colorectal cancer cell lines, including HCT116, LoVo, SW480, and SW620. KDT08 and KDT21 which fall under the same genus Dysidea, possess insignificant cytotoxicity against colorectal cancer cells suggested environmental factors (symbiotic organisms) play a role in biosynthesizing bioactive compounds. Presented results suggested the importance of intensifying research on isolating and purifying natural products from marine sponges for useful applications.
\end{abstract}

Keywords: Marine sponges, Demosponges, Northeast Borneo, Bioactivity, Cell viability

\section{Introduction}

North Borneo, being part of the Coral Triangle and sharing the richness of marine biodiversity, houses various marine ecosystems, including mangroves and coral reefs (Green and Mous, 2008; Hanum et al., 2012). Consistent upwelling in North Borneo waters supplies adequate nutrients to the ecosystems. Nutrients from deeper ocean are brought up through the upwelling process, and help in sustaining the lifeforms in marine ecosystem (Ho et al., 2013). Its unique marine ecosystem is gaining attention from researchers for the rich marine biodiversity (Green and Mous, 2008).

Marine sponges are well known for their richness in bioactive compounds (Blunt et al., 2017). Many compounds are discovered yearly from various marine organisms, and those isolated from marine sponges alone amount to $30 \%$ of the total (Blunt et al., 2016, 2017). The high frequency of bioactive chemicals in marine organisms help them in their survival against predators, fouling organisms, and in spatial competition (Ebada et al., 2010; Perdicaris et al., 2013). Several bioactive compounds discovered from these organisms have biomedical potential and some have already been subjected to clinical trials (Gerwick and Moore, 2012; Mann, 2002).
The study of marine invertebrates was initiated since mid1960s, and thousands of novel compounds had been identified and reported annually (Blunt et al., 2016, 2017; Gerwick and Moore, 2012; Mann, 2002). Among the reported chemical constituents, sasterterpenoids and triterpenoids, are of 25 and 30 carbon chain length, respectively, and are commonly reported from marine sponges. The tests indicated that they possess significant pharmacological properties against a wide range of diseases or infections (Tommonaro et al., 2015).

Over 8000 species of sponges are known (Reegan et al., 2015; Van Soest et al., 2018). However, a complete inventory of sponge diversity in North Borneo is not available (Hooper et al., 2000; Lim et al., 2016). North Borneo is one of the richest marine biodiversity ecosystems in the world and provides enormous scope for discovery of bioactive compounds. This study was undertaken to discover the common sponge species in North Borneo and determine their bioactive compounds effective against human colorectal cancer cell lines. 


\section{Chemicals and reagents}

HPLC-grade methanol and chloroform were procured from Fisher Scientific UK (Loughborough, Leics, UK). Analytical grade hexane and ethyl acetate were purchased from Merck (Darmstadt, Germany). Silica gel (mesh size range at 0.063 $0.200 \mathrm{~mm}$ ) and preparative thin layer chromatography (PTLC) plates coated with $\mathrm{F}_{254}$ fluorescence indicator were obtained from Merck (Darmstadt, Germany). Cell culture mediums, Eagle's minimum essential media (MEM), Dulbecco's modified Eagle's medium (DMEM), Roswell Park Memorial Institute medium (RPMI 1640), accutase, antibiotic mixture $(10,000$ units $/ \mathrm{ml}$ penicillin and $10 \mathrm{mg} / \mathrm{ml}$ streptomycin), 3-(4,5-dimethylthiazol-2-yl)-2,5-diphenyl tetrazolium bromide (MTT) reagent, dimethyl sulfoxide (DMSO), and Hoechst 33342, were obtained from Nacalai Tesque (Kyoto, Japan). Phosphate buffer saline (PBS) was purchased from Merck Millipore (Billerica, MA, USA), and the fetal bovine serum was acquired from Tico Europe (Amstelveen, Netherlands).

\section{Sample collection and extraction}

Samples were collected from Kudat $\left(6^{\circ} 58^{\prime} 32.88 " \mathrm{~N}\right.$, $116^{\circ} 48^{\prime} 48.48 " \mathrm{E}$; and $\left.6^{\circ} 57^{\prime} 45.74^{\prime \prime N}, 116^{\circ} 50^{\prime} 3.72 " \mathrm{E}\right)$ and Maliangin Island $\left(7^{\circ} 4^{\prime} 50.99 " \mathrm{~N}, 117^{\circ} 3^{\prime} 12.00^{\prime \prime E}\right.$; and $7^{\circ}$ $4^{\prime} 25.56^{\prime N}, 117^{\circ} 1^{\prime} 39.24^{\prime \prime E) ~ i n ~ S a b a h ~ u s i n g ~ S C U B A . ~ A ~ t o t a l ~ o f ~}$ 24 sessile sponges (Figure 1) were sampled from Kudat. The depth of all four dive sites was limited to 10-15 m, where benthic marine life is abundant. During sampling, only dominant sponges were harvested. They were kept at low temperature prior to transporting to the laboratory for further processing. A voucher of collection from each specimen was identified by the Swee-Cheng Lim. Liquid nitrogen was employed during grinding, followed by lyophilization and ground samples were stored in $-80{ }^{\circ} \mathrm{C}$ prior to extractions. Homogenized samples were extracted using modified Bligh and Dyer extraction protocol (Bligh and Dyer, 1959). Concisely, polar and non-polar compounds were separated using optimized ratio of water, methanol and chloroform (Lin et al., 2007). A total of $45 \mathrm{~mL}$ of extraction solvents were added to a $0.5 \mathrm{~g}$ sample and kept overnight. Non-polar layer was collected, and solvents were evaporated completely using vacuum concentrator. The crude extracts were kept in $-80{ }^{\circ} \mathrm{C}$ for storage prior to isolation of compounds and other bioassays.

\section{Cell culture and bioactivity screening}

The crude extracts were screened using MTT assay onto human colorectal cancer cell lines (HCT116, LoVo, SW480, and SW620). HCT116 was cultured in MEM; while DMEM for LoVo, SW480, and SW620. These cell lines were supplemented with $10 \%$ of fetal bovine serum and $1 \%$ of antibiotic mixture and maintained in a humidified incubator in $5 \% \mathrm{CO}_{2}$ at $37^{\circ} \mathrm{C}$. Extracted compound was reconstituted in DMSO and diluted into a series of concentrations before adding to the culture medium.

Approximately 5,000 cells were seeded with $100 \mu \mathrm{L}$ of culture medium in each 96-well plate for overnight before treatment with the isolated compound where the culture medium was replaced with a new medium together with $1 \%$ of DMSO dissolved extract. After $24 \mathrm{~h}$ treatment, the culture medium was removed and added with $50 \mu \mathrm{L}$ of $0.5 \mathrm{mg} / \mathrm{ml}$ MTT solution, followed by $1 \mathrm{~h}$ incubation. Then, MTT solution was removed gently and each well was refilled with $100 \mu \mathrm{L}$ of DMSO. Absorbance value was determined with a Tecan Infinite 200 Pro microplate reader (Männedorf, Switzerland) at $570 \mathrm{~nm}$.

\section{Results and Discussion}

Among the collected specimens, KDT01 was identified as colonial ascidian from family Didemnidae, whereas the rest were demosponges from order Agelasida $(n=2)$, Axinellida $(n=3)$, Dictyoceratida $(n=4)$, Haplosclerida $(n=8)$, Poecilosclerida $(n=3)$, Tetractinellida $(n=2)$, and Verongiida $(n=1)$. Taxonomic details of the demosponges are described in Table 1 . In cell viability screening (Figure $2 \mathrm{a}$ and b), KDT01 has shown the highest effectiveness against human colorectal cancer cell lines (HCT116, LoVo, SW480, and SW620), followed by KDT07, KDT09, and KDT18.

Numerous researches have noticed that ascidians from family Didemnidae consisting of symbiotic prokaryotic algae, yield structurally unique and pharmacologically interesting marine natural products including didemnins, enterocins, tamandarins, paterallazoles, and virenamides (Vervoort et al., 2000; Ogi et al., 2008; Palanisamy et al., 2017). Several polysulfur alkaloids (lissoclibadins 1-3) had been isolated from a close relative of KDT01, Lissoclinum sp.; they were found to possess cytotoxicity against human promyelocytic leukemia cell line (HL-60) with IC 50 of 0.37 , 0.21 , and $5.5 \mu \mathrm{M}$, respectively (Liu et al., 2005; Palanisamy et al., 2017).

In our study, KDT07, KDT09, and KDT18 are among the demosponges which possess significant cytotoxicity against colorectal cancer cell lines, and they were identified as Monanchora clathrata, Dysidea sp., and Jaspis sp., respectively (Figure $2 \mathrm{a}$ and $\mathrm{b}$ ). Species from Monanchora are known for their bioactive polycyclic guanidine alkaloids (Hua et al., 2004; Gallimore et al., 2005; Takishima et al., 2009). Monanchocidin, a polycyclic guanidine alkaloid, isolated from $M$. pulchra possesses pro-apoptotic effects against human cervix epithelioid carcinoma cells (HeLa) at IC50 $11.8 \mu \mathrm{M}$ (Guzii et al., 2010). 


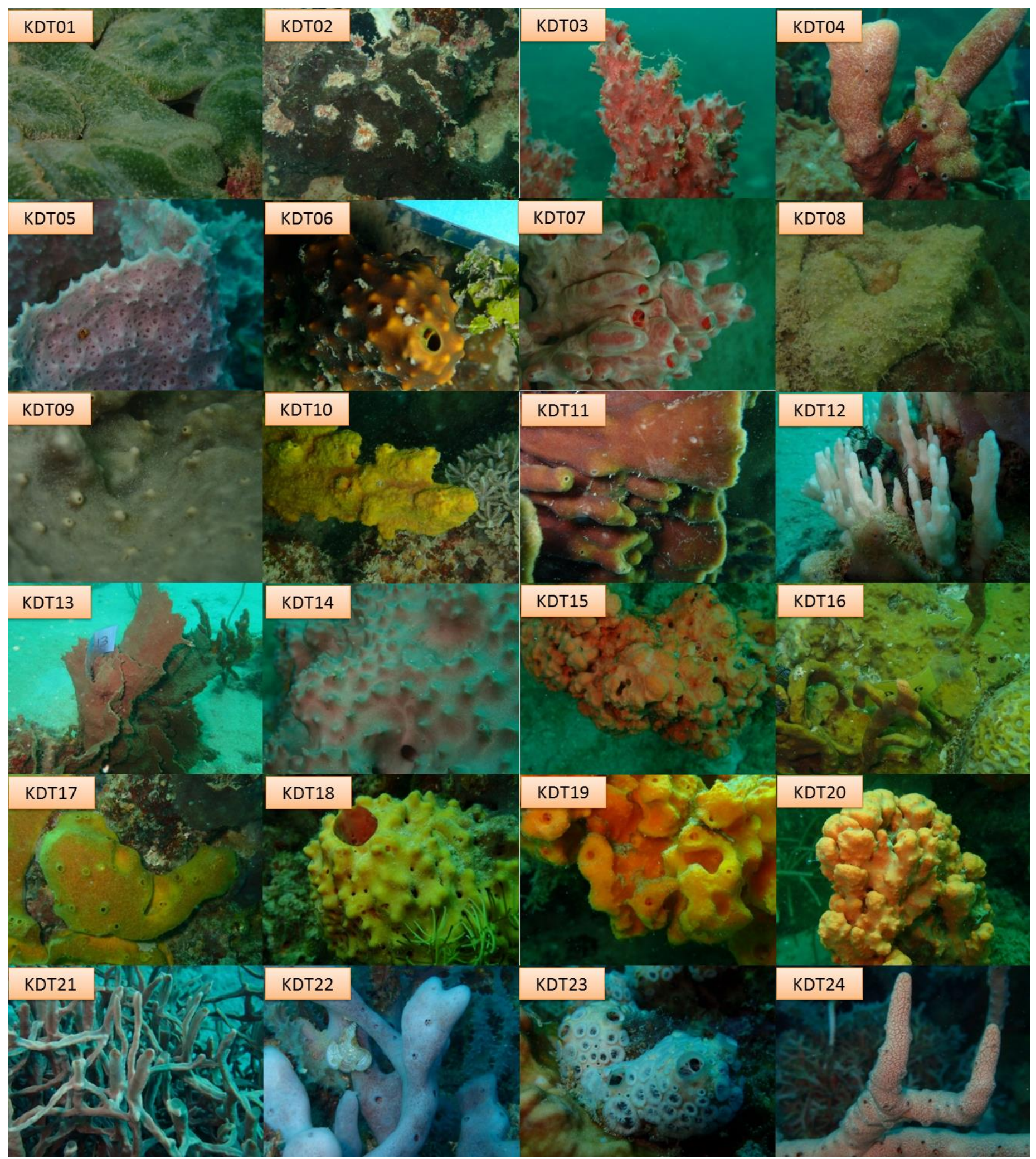

Figure 1. Underwater images of the collected sponge-like invertebrates. 
Table 1. Sponges collected from Northeast Borneo.

\begin{tabular}{|c|c|c|}
\hline Family & Species & Specimen \\
\hline \multicolumn{3}{|l|}{ Order Agelasida } \\
\hline Agelasidae & Agelas sp. & KDT15 \\
\hline Agelasidae & Agelas sp. & KDT20 \\
\hline \multicolumn{3}{|l|}{ Order Axinellida } \\
\hline Axinellidae & Axinella sp. & KDT10 \\
\hline Raspailiidae & Raspailia sp. & KDT03 \\
\hline Raspailiidae & Echinodictyum mesenerium & KDT05 \\
\hline \multicolumn{3}{|c|}{ Order Dictyoceratida } \\
\hline Dysideidae & Dysidea sp. & KDT08 \\
\hline Dysideidae & Dysidea sp. & KDT09 \\
\hline Dysideidae & Dysidea sp. & KDT21 \\
\hline Irciniidae & Ircinia cf. irregularis & KDT14 \\
\hline \multicolumn{3}{|c|}{ Order Haplosclerida } \\
\hline Chalinidae & Cladocroce sp. & KDT22 \\
\hline Niphatidae & Cribrochalina sp. & KDT13 \\
\hline Petrosiidae & Xestospongia sp. & KDT02 \\
\hline Petrosiidae & Petrosia sp. & KDT04 \\
\hline Petrosiidae & Petrosia sp. & KDT11 \\
\hline Petrosiidae & Petrosia sp. & KDT16 \\
\hline Petrosiidae & Petrosia sp. & KDT17 \\
\hline Phloeodictyidae & Siphonodictyon maldiviense & KDT12 \\
\hline \multicolumn{3}{|c|}{ Order Poecilosclerida } \\
\hline Crambeidae & Monanchora clathrata & KDT07 \\
\hline Microcionidae & Clathria sp. & KDT24 \\
\hline Tedaniidae & Tedania sp. & KDT23 \\
\hline \multicolumn{3}{|c|}{ Order Tetractinellida } \\
\hline Ancorinidae & Jaspis sp. & KDT18 \\
\hline Ancorinidae & Jaspis splendens & KDT19 \\
\hline \multicolumn{3}{|l|}{ Order Verongiida } \\
\hline Pseudoceratinidae & Pseudoceratina sp. & KDT06 \\
\hline
\end{tabular}

*KDT01 was excluded due to its identity as colonial ascidian.

** Most of the specimens could not be identified to species level. 


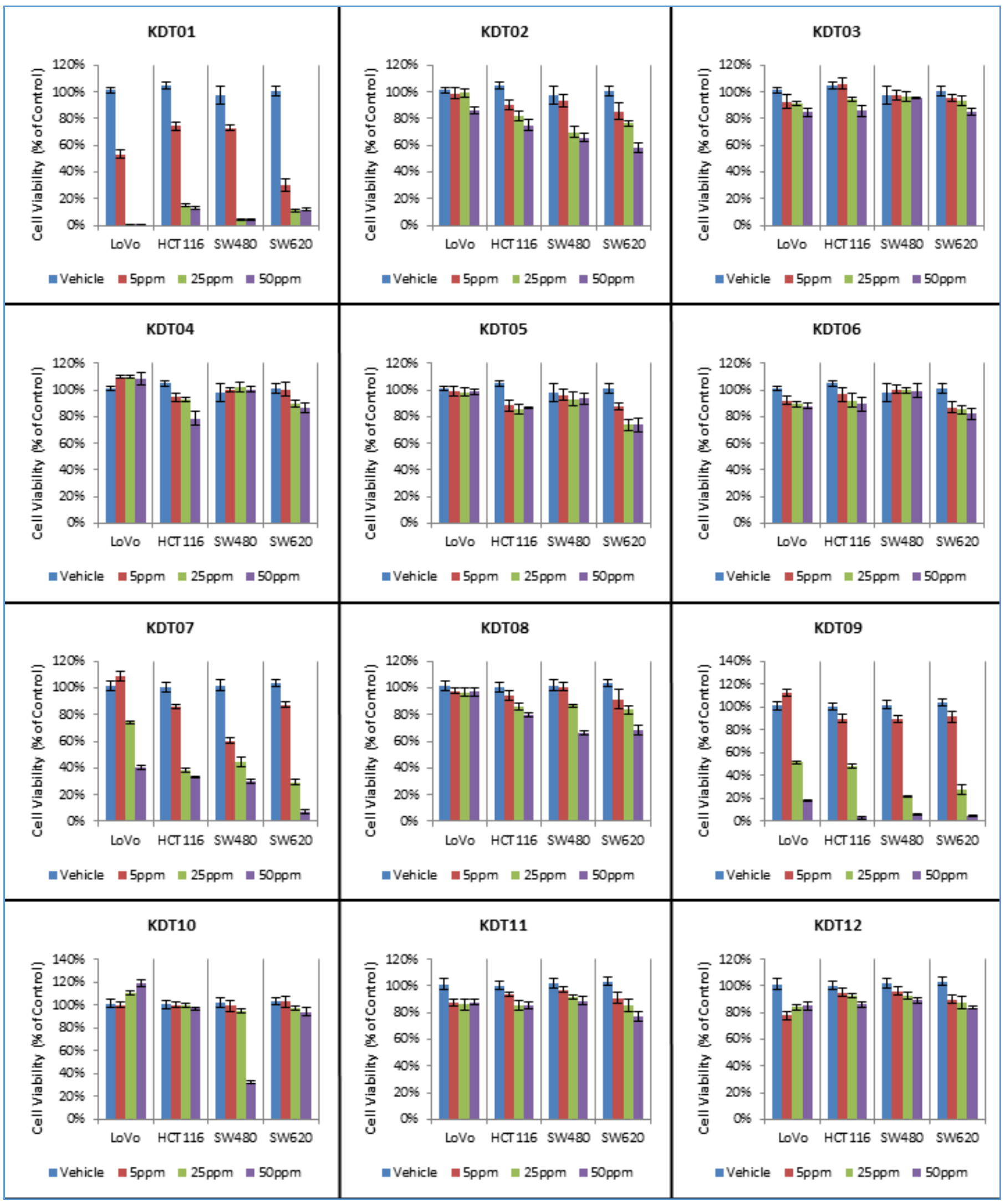

Figure 2a. Cytotoxicity of crude extracts against human colorectal cancer cell lines. 


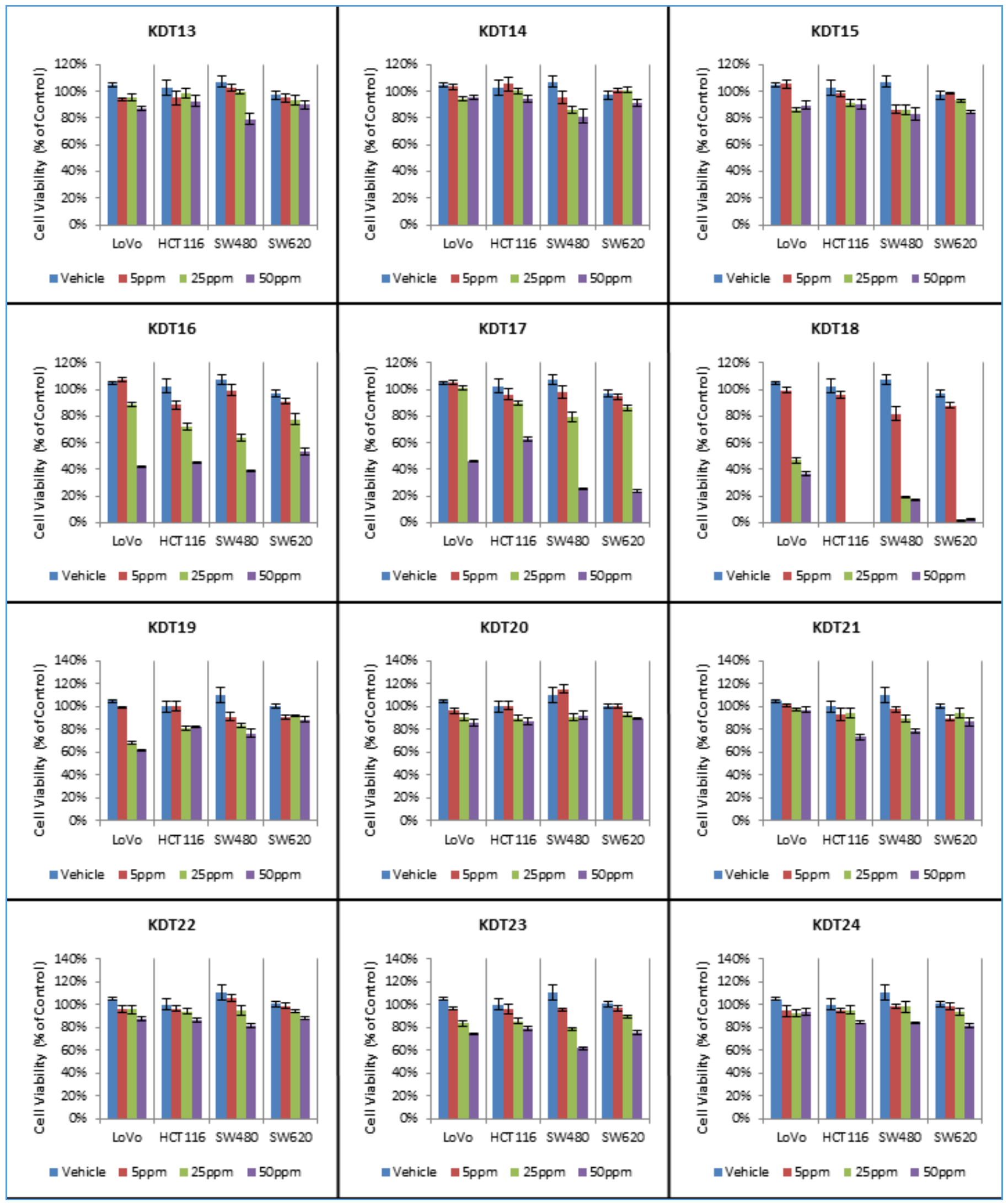

Figure 2b. Cytotoxicity of crude extracts against human colorectal cancer cell lines. 
Dysidea are well-known for their unique cytotoxic terpenes. Dysideanones and dysiherbols are some of the representative sesquiterpene quinones and meroterpenes isolated from Dysidea collected from South China Sea, which were found to inhibit human cancer cells (Jiao et al., 2014; Jiao et al., 2016) . Researches revealed that dysideanone B possessed cytotoxicity against human cervix epithelioid carcinoma cells (HeLa) and human hepatoma cells (HepG2) with IC 50 of 7.1 and $9.4 \mu \mathrm{M}$, respectively (Jiao et al., 2014), whereas dysiherbol A showed potent cytotoxic activity against human myeloma cancer cells (NCI H-929) with IC 50 of $0.58 \mu \mathrm{M}$ (Jiao et al., 2016). Jaspis, as compared to other identified sponges in our study, was reported rich in cytotoxic metabolites, with potential cancer- inhibition properties. Jaspiferals and stelliferins are some of the examples of antineoplastic terpenoids isolated from Jaspis sponges with active cytotoxicity against various cancer cell lines (Tsuda et al., 1991; Kobayashi et al., 1996; Zampella et al., 2000; Mergelman et al., 2001). Cytotoxicity of stelliferins A-F and jaspiferals A-G isolated from Okinawan Jaspis stellifera was reported since early 1990s. The jaspiferals G and stelliferin A exhibited the highest cytotoxicity against murine lymphoma L1210 cells with IC $\mathrm{C}_{50}$ of 0.54 and 0.57 $\mu \mathrm{g} / \mathrm{mL}$, respectively (Kobayashi et al., 1996; Tsuda et al., 1991). Jaspis also contains various groups of antineoplastic compounds, such as macrocyclic peptides (jaspamides), macrolides (jaspisamides), and heterocyclic compounds (bengamides and bengazoles)(Kobayashi et al., 1993; Bubb et al., 1994; Senderowicz et al., 1995; Groweiss et al., 1999; Zampella et al., 1999). Evidently, Jaspis sp. has a higher potential in novel oncological drug discovery.

The production of chemically active and structurally unique compounds by sponges depends on various factors, including the variety of symbionts, symbiotic microbial interactions, external biotic and abiotic stress (Hentschel et al., 2001; Belarbi et al., 2003; Page et al.,2005). Alteration in environmental factors alters the symbiont population and yield of different chemicals. Therefore, genetically identical sponges are found to possess chemical variation across various abiotic factors (Page et al., 2005). This explains why KDT08 and KDT21 do not possess cytotoxicity unlike their close relative, KDT09, and similar phenomena was observed in Jaspis.

\section{Conclusion}

A total of 23 sponges were harvested, out of which three were found to possess significant bioactivity against human colorectal cancer cells and have high pharmaceutical value. These sponges were identified as Monanchora clathrata, Dysidea sp., and Jaspis sp. The presence of bioactive compounds in sponges depends on both internal and external factors. In conclusion, KDT18 (Jaspis sp.) possesses a greater potential in drug discovery and is recommended for thorough studies, including isolation of bioactive compounds, followed by pharmacokinetic and pharmacodynamics studies on the isolated compounds.

\section{Acknowledgements}

The authors wish to thank the Ministry of Higher Education, Malaysia for funding the research (FRGS0428-SG-1/2015), and North Borneo Biostation Resort for support. We are particularly grateful to Prof. Dr. Alexander Frank, Director, and the in-house PADI instructor, Mr. Manel Andrade.

\section{References}

Belarbi, E. H., Contreras Gómez, A., Chisti, Y., Garcl, x, a Camacho, F., \& Molina Grima, E. (2003). Producing drugs from marine sponges. Biotechnology Advances 21(7), 585-598. doi:https://doi.org/10.1016/S0734-9750(03)00100-9

Bligh, E. G., \& Dyer, W. J. (1959). A rapid method of total lipid extraction and purification. Canadian Journal of Biochemistry and Physiology 37(8), 911-917. doi:https://doi.org/10.1139/o59-099

Blunt, J. W., Copp, B. R., Keyzers, R. A., Munro, M. H. G., \& Prinsep, M. R. (2016). Marine natural products. Natural Product Reports 33(3), 382-431. doi:https://doi.org/10.1039/C5NP00156K

Blunt, J. W., Copp, B. R., Keyzers, R. A., Munro, M. H. G., \& Prinsep, M. R. (2017). Marine natural products. Natural Product Reports 34(3), 235-294. doi:https://doi.org/10.1039/C6NP00124F

Bubb, M. R., Senderowicz, A. M., Sausville, E. A., Duncan, K. L., \& Korn, E. D. (1994). Jasplakinolide, a cytotoxic natural product, induces actin polymerization and competitively inhibits the binding of phalloidin to Factin. Journal of Biological Chemistry 269(21), 14869-14871

Ebada, S. S., Lin, W., \& Proksch, P. (2010). Bioactive Sesterterpenes and Triterpenes from Marine Sponges: Occurrence and Pharmacological $\begin{array}{llll}\text { Significance. Marine } & \text { Drugs }\end{array}$ doi:https://doi.org/10.3390/md8020313

Gallimore, W. A., Kelly, M., \& Scheuer, P. J. (2005). Alkaloids from the Sponge Monanchora unguifera. Journal of Natural Products 68(9), 14201423. doi:https://doi.org/10.1021/np050149u

Gerwick, William H., \& Moore, Bradley S. (2012). Lessons from the Past and Charting the Future of Marine Natural Products Drug Discovery and Chemical Biology. Chemistry \& Biology 19(1), 85-98. doi:http://dx.doi.org/10.1016/j.chembiol.2011.12.014

Green, A., \& Mous, P. (2008). Delineating the Coral Triangle, its ecoregions and functional seascapes Version 5.0. TNC Coral Triangle Program Report 1(08.44)

Groweiss, A., Newcomer, J. J., O'Keefe, B. R., Blackman, A., \& Boyd, M. R. (1999). Cytotoxic Metabolites from an Australian Collection of the Sponge Jaspis Species. Journal of Natural Products 62(12), 1691-1693. doi:https://doi.org/10.1021/np9902688

Guzii, A. G., Makarieva, T. N., Denisenko, V. A., Dmitrenok, P.S., Kuzmich, A. S., Dyshlovoy, S. A., Krasokhin, V. B., \& Stonik, V. A. (2010). Monanchocidin: A New Apoptosis-Inducing Polycyclic Guanidine Alkaloid from the Marine Sponge Monanchora pulchra. Organic Letters 12(19), 4292-4295. doi:https://doi.org/10.1021/ol101716x

Hanum, F., Kudus, K., \& Saari, N. (2012). Plant diversity and biomass of Marudu bay mangroves in Malaysia. Pakistan Journal of Botany 44, 151156

Hentschel, U., Schmid, M., Wagner, M., Fieseler, L., Gernert, C., \& Hacker, J. (2001). Isolation and phylogenetic analysis of bacteria with antimicrobial activities from the Mediterranean sponges Aplysina aerophoba and Aplysina cavernicola. FEMS Microbiology Ecology 35(3), 305-312. doi:https://doi.org/10.1111/j.1574-6941.2001.tb00816.x 
Ho, D. J., Maryam, D. S., Madihah, J.-S., \& Than, A. (2013). Influence of weather condition on pelagic fish landings in Kota Kinabalu, Sabah, Malaysia. Journal of Tropical Biology and Conservation 10(1), 11-21

Hooper, J., Kennedy, J., \& Van Soest, R. (2000). Annotated checklist of sponges (Porifera) of the South China Sea region. The Raffles Bulletin of Zoology Supplement Series No. 8, 125-207

Hua, H.-m., Peng, J., Fronczek, F. R., Kelly, M., \& Hamann, M. T. (2004). Crystallographic and NMR studies of antiinfective tricyclic guanidine alkaloids from the sponge Monanchora unguifera. Bioorganic \& Medicinal Chemistry 12(24), doi:https://doi.org/10.1016/j.bmc.2004.09.026 6461-6464.

Jiao, W.-H., Shi, G.-H., Xu, T.-T., Chen, G.-D., Gu, B.-B., Wang, Z., Peng, S., Wang, S.-P., Li, J., Han, B.-N., Zhang, W., \& Lin, H.-W. (2016). Dysiherbols A-C and Dysideanone $\mathrm{E}$, Cytotoxic and NF- $\kappa \mathrm{B}$ Inhibitory Tetracyclic Meroterpenes from a Dysidea sp. Marine Sponge. Journal of Natural Products 79(2), 406-411. doi:https://doi.org/10.1021/acs.jnatprod.5b01079

Jiao, W.-H., Xu, T.-T., Yu, H.-B., Chen, G.-D., Huang, X.-J., Yang, F., Li, Y.-S., Han, B.-N., Liu, X.-Y., \& Lin, H.-W. (2014). Dysideanones A-C, Unusual Sesquiterpene Quinones from the South China Sea Sponge Dysidea avara.

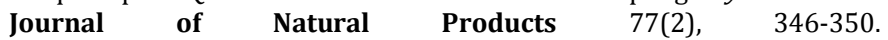
doi:https://doi.org/10.1021/np4009392

Kobayashi, J. i., Murata, O., Shigemori, H., \& Sasaki, T. (1993). Jaspisamides A-C, New Cytotoxic Macrolides from the Okinawan Sponge Jaspis Sp. Journal of Natural Products 56(5), 787-791. doi:https://doi.org/10.1021/np50095a021

Kobayashi, J. i., Yuasa, K., Kobayashi, T., Sasaki, T., \& Tsuda, M. (1996). Jaspiferals $A \sim G$, new cytotoxic isomalabaricane-type nortriterpenoids from Okinawan marine sponge Jaspis stellifera. Tetrahedron 52(16), 5745-5750. doi:http://dx.doi.org/10.1016/0040-4020(96)00206-2

Lim, S.-C., Putchakarn, S., Thai, Q., Wang, D., \& Huang, Y. (2016). Inventory of sponge fauna from the Singapore Strait to Taiwan Strait along the western coastline of the South China Sea. The Raffles Bulletin of Zoology Supplement Series No. 34, 104-129

Lin, C., Wu, H., Tjeerdema, R., \& Viant, M. (2007). Evaluation of metabolite extraction strategies from tissue samples using NMR metabolomics. Metabolomics 3(1), 55-67. doi:https://doi.org/10.1007/s11306-006-0043-1

Liu, H., Fujiwara, T., Nishikawa, T., Mishima, Y., Nagai, H., Shida, T., Tachibana, K., Kobayashi, H., Mangindaan, R. E. P., \& Namikoshi, M. (2005). Lissoclibadins 1-3, three new polysulfur alkaloids, from the ascidian Lissoclinum cf. badium. Tetrahedron 61(36), 8611-8615. doi:https://doi.org/10.1016/j.tet.2005.07.002

Mann, J. (2002). Natural products in cancer chemotherapy: Past, present and future. Nat Rev Cancer 2(2), 143-148. doi:https://doi.org/10.1038/nrc723

Meragelman, K. M., McKee, T. C., \& Boyd, M. R. (2001). New Cytotoxic Isomalabaricane Triterpenes from the Sponge Jaspis Species. Journal of Natural Products 64(3), 389-392. doi:https://doi.org/10.1021/np000478g

Ogi, T., Taira, J., Margiastuti, P., \& Ueda, K. (2008). Cytotoxic Metabolites from the Okinawan Ascidian Diplosoma virens. Molecules 13(3), 595. doi:https://doi.org/10.3390/molecules13030595

Page, M. J., Northcote, P. T., Webb, V. L., Mackey, S., \& Handley, S. J. (2005). Aquaculture trials for the production of biologically active metabolites in the New Zealand sponge Mycale hentscheli (Demospongiae: Poecilosclerida). Aquaculture 250(1), 256-269. doi:https://doi.org/10.1016/j.aquaculture.2005.04.069

Palanisamy, S. K., Rajendran, N. M., \& Marino, A. (2017). Natural Products Diversity of Marine Ascidians (Tunicates; Ascidiacea) and Successful Drugs in Clinical Development. Natural Products and Bioprospecting 7(1), 1-111. doi:https://doi.org/10.1007/s13659-0160115-5

Perdicaris, S., Vlachogianni, T., \& Valavanidis, A. (2013). Bioactive natural substances from marine sponges: new developments and prospects for future pharmaceuticals. Natural Products Chemistry \& Research 1(3), 1-8. doi:http://dx.doi.org/10.4172/2329-6836.1000115

Reegan, A. D., Kinsalin, A. V., Paulraj, M. G., \& Ignacimuthu, S. (2015). Larvicidal, ovicidal, and repellent activities of marine sponge Cliona celata (Grant) extracts against Culex quinquefasciatus Say and Aedes aegypti L.(Diptera: Culicidae). Asian Pacific Journal of Tropical Medicine 8(1), 29-34. doi:https://doi.org/10.1016/S1995-7645(14)60183-8

Senderowicz, A. M. J., Kaur, G., Sainz, E., Laing, C., Inman, W. D., Rodriguez, J., Crews, P., Malspeis, L., Grever, M. R., Sausville, E. A., \& Duncan, K. L. K. (1995). Jasplakinolide's Inhibition of the Growth of Prostate Carcinoma Cells In Vitro With Disruption of the Actin Cytoskeleton. JNCI: Journal of the National Cancer Institute 87(1), 46-51. doi:https://doi.org/10.1093/jnci/87.1.46

Takishima, S., Ishiyama, A., Iwatsuki, M., Otoguro, K., Yamada, H., Õmura, S., Kobayashi, H., van Soest, R. W. M., \& Matsunaga, S. (2009). Merobatzelladines A and B, Anti-Infective Tricyclic Guanidines from a Marine Sponge Monanchora sp. Organic Letters 11(12), 2655-2658. doi:https://doi.org/10.1021/ol9006794

Tommonaro, G., De Rosa, S., Carnuccio, R., Maiuri, M. C., \& De Stefano, D. (2015). Marine Sponge Sesterpenoids as Potent Apoptosis-Inducing Factors in Human Carcinoma Cell Lines. In S.-K. Kim (Ed.), Handbook of Anticancer Drugs from Marine Origin (pp. 439-479): Springer International Publishing.doi:https://doi.org/10.1007/978-3-319-07145-9_22

Tsuda, M., Ishibashi, M., Agemi, K., Sasaki, T., \& Kobayashi, J. i. (1991). Stelliferins A-F, new antineoplastic isomalabaricane triterpenes from the Okinawan marine sponge Jaspis stellifera. Tetrahedron 47(12), 2181-2194. doi:https://doi.org/10.1016/S0040-4020(01)96129-0

Van Soest, R. W. M., Boury-Esnault, N., Hooper, J. N. A., Rützler, K., de Voogd, N. J., Alvarez, B., Hajdu, E., Pisera, A. B., Manconi, R., Schönberg, C., Klautau, M., Picton, B., Kelly, M., Vacelet, J., Dohrmann, M., Díaz, M.-C., Cárdenas, P., Carballo, J. L., Ríos, P., \& Downey, R. (2018). World Porifera Database. Retrieved on $3 / 2 / 2018$ from http://www.marinespecies.org/porifera

Vervoort, H., Fenical, W., \& Epifanio, R. d. A. (2000). Tamandarins A and B: New Cytotoxic Depsipeptides from a Brazilian Ascidian of the Family Didemnidae. The Journal of Organic Chemistry 65(3), 782-792. doi:https://doi.org/10.1021/jo991425a

Zampella, A., D'Auria, M. V., Debitus, C., \& Menou, J.-L. (2000). New Isomalabaricane Derivatives from a New Species of Jaspis Sponge Collected at the Vanuatu Islands. Journal of Natural Products 63(7), 943-946. doi:https://doi.org/10.1021/np000088u

Zampella, A., Giannini, C., Debitus, C., Roussakis, C., \& D'Auria, M. V. (1999). New Jaspamide Derivatives from the Marine Sponge Jaspis splendans Collected in Vanuatu. Journal of Natural Products 62(2), 332-334. doi:https://doi.org/10.1021/np9803225 